\title{
Structural deformation of branching corals associated with the vermetid gastropod Dendropoma maxima
}

\author{
Assaf Zvuloni ${ }^{1,2, *}$, Rachel Armoza-Zvuloni ${ }^{1,2}$, Yossi Loya ${ }^{1}$ \\ ${ }^{1}$ Department of Zoology, The George S. Wise Faculty of Life Sciences, Tel Aviv University, Tel Aviv 69978, Israel \\ ${ }^{2}$ The H. Steinitz Marine Biology Laboratory, the Interuniversity Institute for Marine Sciences of Eilat, PO Box 469, \\ Eilat 88103, Israel
}

\begin{abstract}
The vermetid gastropod Dendropoma maxima is found in association with diverse coral species. This association is often characterized by the coral head covered by a wide mucus net secreted by the gastropod to trap food particles from the water column. Here we report on the quantitative effect of the gastropod on the morphology of Stylophora pistillata, one of the most abundant branching corals on the reef flat in Eilat (Gulf of Aqaba/Eilat, Red Sea). The existence of D. maxima in the vicinity of corals plays a significant role in deforming coral morphology. Compared with corals located outside the influence range of D. maxima, affected corals were found to be approx. 52\% lower in their vertical dimension and approx. $35 \%$ smaller in diameter, and their slenderness ratio (height:diameter ratio) was found to be approx. $35 \%$ smaller. In addition, we found that over the last decade the population of $D$. maxima on the reef flat in Eilat has significantly increased in density (by a factor of approx. 2.5). The reason for this dramatic increase is currently unknown. However, it may be linked to the reported eutrophication of the northern Gulf of Aqaba, as this kind of environmental shift enhances the competitive advantage of suspension feeders over corals. Thus, the increase in the gastropod abundance may be a precursor of change in the reef flat community structure.
\end{abstract}

KEY WORDS: Dendropoma maxima - Scleractinian coral · Competition · Deformation · Eilat · Reef flat $\cdot$ Slenderness ratio

\section{INTRODUCTION}

Direct and indirect competition between scleractinian corals and their associated organisms may be a critical process in determining the abundance of corals on reefs, especially under conditions of reef degradation due to anthropogenic disturbances (e.g. eutrophication; Smith et al. 1981, Hunter \& Evans 1995, McCook 2001, Loya 2007). The vermetid gastropod Dendropoma maxima Sowerby, 1825, is a common inhabitant of IndoPacific coral reefs. It is abundant on shallow reef flats, at sites exposed to waves (Hughes \& Lewis 1974, Smalley 1984, Ribak et al. 2005). This sessile gastropod has an irregularly uncoiled shell that is cemented to the substrate
(Keen 1961). It feeds by secreting a mucus net that originates from a large pedal gland and spreads into the water via special grooved tentacles. The net remains in the water for 20 to $40 \mathrm{~min}$, close to the substrate, after which it is retracted into the mouth and ingested, together with all the trapped particles (Morton 1950, Hughes \& Lewis 1974). The gastropod's diet consists mostly of plankton, meiobenthos and detritus (Kappner et al. 2000). The use of mucus nets for suspension feeding is unique because, unlike most passive suspension feeders that have a fixed filtering organ, the mucus net can change in size and shape in response to different current conditions and its area can be many times larger than the size of the animal itself (Ribak et al. 2005). 
Dendropoma maxima is found in association with diverse coral species (Colgan in Smalley 1984, Zuschin et al. 2001, Fenner 2006). This association may be considered competitive, since the corals and gastropods overlap in their use of resources. Both organisms rely on water flow for the delivery of food and nutrients, gas exchange and reproduction, and thus compete for substrate upon which to grow. Therefore, limiting or reducing the growth of one competitor provides the other with a competitive advantage. Although the D. maxima-coral association is very common on reef flats in the Red Sea (authors' pers. obs.) and has also been observed in other locations, such as American Samoa (Pacific Ocean; Fenner 2006) and along the east coast of Zanzibar (western Indian Ocean; A. Zvuloni pers. obs.), the competitive interactions between gastropods and corals have been only poorly described and not tested quantitatively.

We report on the quantitative effect of gastropods on coral morphology. In addition, we compare the abundance of Dendropoma maxima with that reported by Ribak et al. (2005), who studied the distribution of this gastropod at the same locations 9 yr earlier. The latter finding may contribute to assessing the competitive dynamics that take place between corals and gastropods on the reef flat.

\section{MATERIALS AND METHODS}

Study sites. Our analyses were based on the quantitative survey conducted in April 2007 on the reef flat in a depth of approx. $0.5 \mathrm{~m}$, in an area of the Eilat Coral Nature Reserve closed to visitors (northern tip of the Gulf of Aqaba/Eilat, Red Sea; 29 30'17.6" N, $\left.34^{\circ} 55^{\prime} 09.5^{\prime \prime} \mathrm{E}\right)$. The site was chosen following Ribak et al. (2005), to obtain a spatio-temporal perspective of the coral-gastropod co-existence.

Effect of the gastropod on coral morphology. The spatial influence of the gastropods' mucus nets on coral morphology was tested using the slenderness ratio (SR; height:diameter ratio) of corals as a morphological variable that may indicate irregular growth. The species chosen was the branching coral Stylophora pistillata because of its high abundance on the reef flat and its relatively rounded shape; i.e. this ensures that, in contrast to other species (e.g. Acropora spp.), the SR of this species does not vary much between colonies of different size classes. We hypothesized that, should deformation be caused by the coral's association with the gastropod, the natural SR of the corals would be affected. To test this, a belt transect of $75 \mathrm{~m}$ by $1 \mathrm{~m}$ was placed along the seaward edge of the reef flat (where the density of this gastropod is highest), defining the sampled area. Each of the 122 colonies within the sam- pled area was measured for its height and diameter, and for its proximity to the nearest Dendropoma maxima. The 'center rules' counting scheme (Zvuloni et al. 2008) was used to prevent preferential sampling of certain coral size-classes. If the shape of the corals is indeed affected by the gastropods, we assume that within the gastropod's range of influence, the SR of corals will change as a function of their distance from the gastropod. On the other hand, outside the range of influence, the SR of corals should not be affected.

Abundance of Dendropoma maxima across the reef flat. The abundance of the gastropod across the reef flat was estimated using the same methodology as used by Ribak et al. (2005). Three $100 \mathrm{~m}$ long transects were placed along 3 zones across the reef flat: the seaward edge, mid-reef and shoreward edge (for more details, see transects B, C and D in Fig. 1 of Ribak et al. [2005]). Twenty $1 \times 1 \mathrm{~m}$ quadrats were randomly placed along each of these 3 long transects and the number of gastropods within each of the quadrats was recorded. Abundance estimates of Dendropoma maxima found in the present study were compared with those of Ribak et al. (2005), obtained 9 yr previously.

Statistical analysis. To estimate the range of possible influence of the gastropod on coral morphology, we conducted a piecewise linear regression (PLR) analysis (StatSoft, 2003 version) as a statistical technique to model ecological thresholds (see Toms \& Lesperance 2003) on the SR values as a function of the distance from the nearest Dendropoma maxima. This analysis estimates the 'breakpoint' of the data, at which the distance from the gastropod does not affect the SR of the corals. The breakpoint estimated by the PLR analysis was used to separate the corals into 2 groups: those within the radius of influence of the gastropod, and those outside it. The 2 groups were then statistically compared for their height, diameter and SR using the Kolmogorov-Smirnov 2 -sample test (KS test). Abundance estimates of the gastropod obtained in the present study were compared with those of Ribak et al. (2005) using 2-way ANOVA followed by a Tukey's post hoc test. In addition, the spatial spread pattern of the gastropods was tested using the index of dispersion (ID), defined as the variance to mean ratio of the number of gastropods in the quadrats (Southwood \& Henderson 2000).

\section{RESULTS}

\section{Qualitative description of the gastropod-coral association}

The gastropod-coral association (whether the gastropod is embedded within the coral tissue or cemented nearby the coral) was often characterized by the gastropod's mucus net covering the coral head. 


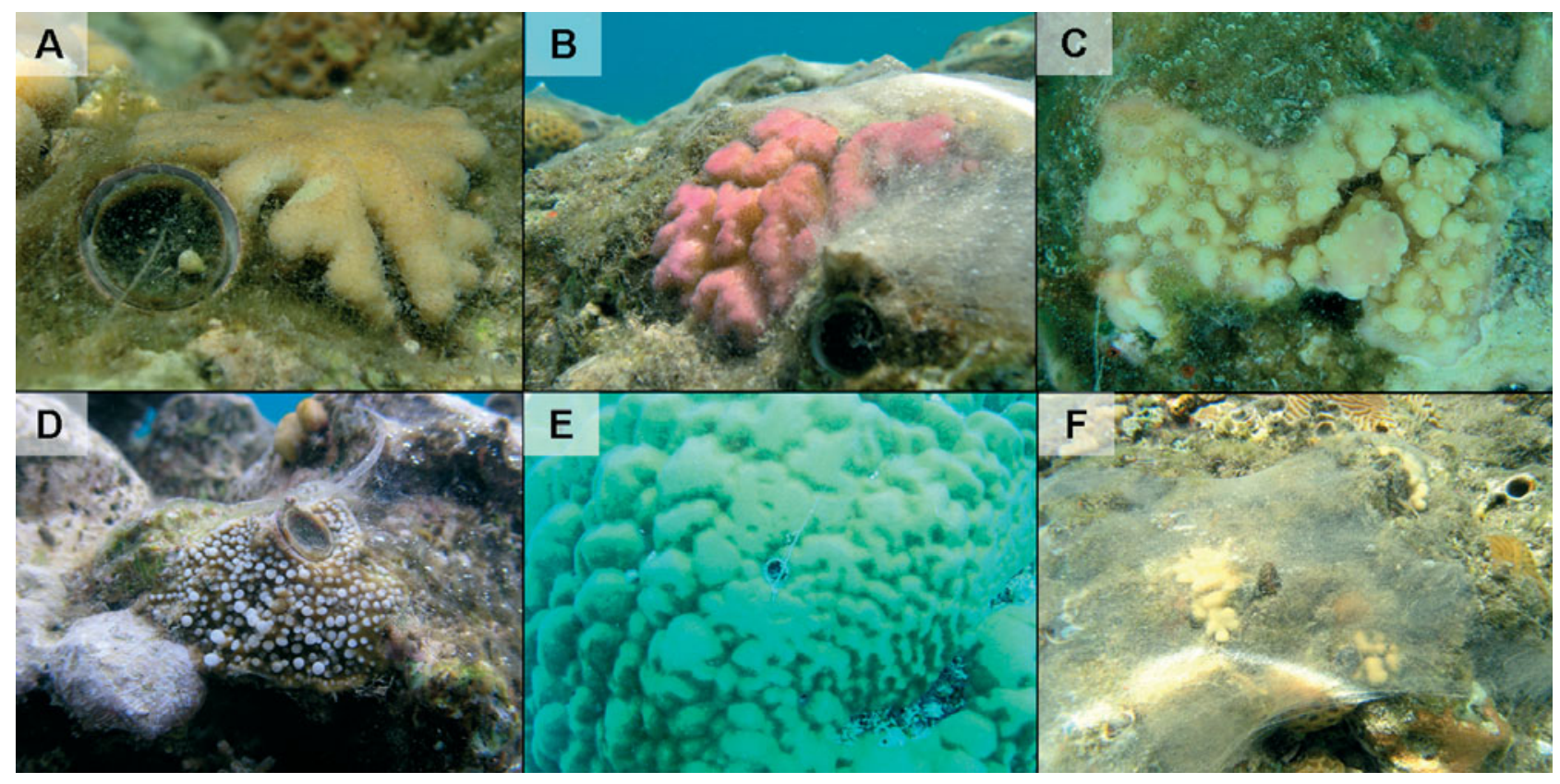

Fig. 1. Irregular growth of corals associated with the vermetid gastropod Dendropoma maxima. (A) Stylophora pistillata: flattened shape; (B) Pocillopora damicornis: smooth and flat branch tips; (C and D) Acropora sp.: flattened shape and loss of the coral's typical terminal polyps; (E) Porites lobata: the area around the gastropod exhibits an even surface; (F) mucus nets secreted by different individuals merge and cover large areas of the reef's surface, including corals

The morphology of branching corals associated with Dendropoma maxima was observed to be dramatically affected by the gastropod's mucus net (Fig. 1A-D). Corals, such as Stylophora pistillata, Pocillopora damicornis, Acropora spp. and the hydrozoan Millepora dichotoma that have been covered by the mucus net are relatively small and characterized by an abnormal flattened shape. These corals possess unusually dense and thick branches with smooth tips. The most significant deformation was observed in Acropora sp., in which branch tips had lost their typical terminal polyps (Fig. 1C,D). It appears that the mucus net defines and limits the maximum growth level of the coral branches, leading to a flat-shaped colony. The mucus net covering the coral head is often so thick and dense that gas bubbles get trapped under the net, touching the coral surface (Fig. 1C). The morphology of massive corals also appeared to be affected in areas where the mucus net touched the coral tissue. The polyps at such locations are often smooth and flattened. If a coral has a naturally uneven surface, such as the massive coral Porites lobata, the area touching the mucus net frequently exhibits a more even surface (e.g. Fig. 1E). In some areas on the reef flat in Eilat, especially along the seaward edge, the mucus nets secreted by different individuals merge to become a larger net covering large areas of the reef surface (several $\mathrm{m}^{2}$ ), encompassing corals and other organisms that grow on this substrate (Fig. 1F).

\section{Effect of the gastropod on coral morphology}

The PLR analysis estimated the breakpoint of the data (SR versus distance from the nearest Dendropoma maxima) as $27.5 \mathrm{~cm}\left(\mathrm{R}^{2}=0.71,95 \%\right.$ confidence interval $[\mathrm{CI}]=21.7$ to $33.3 \mathrm{~cm}$ ), as an indication for the radius of influence of the gastropod on the SR of surrounding corals (Fig. 2). The SR displays a significant increase prior to a distance of $27.5 \mathrm{~cm}(0.025 / \mathrm{cm})$ and

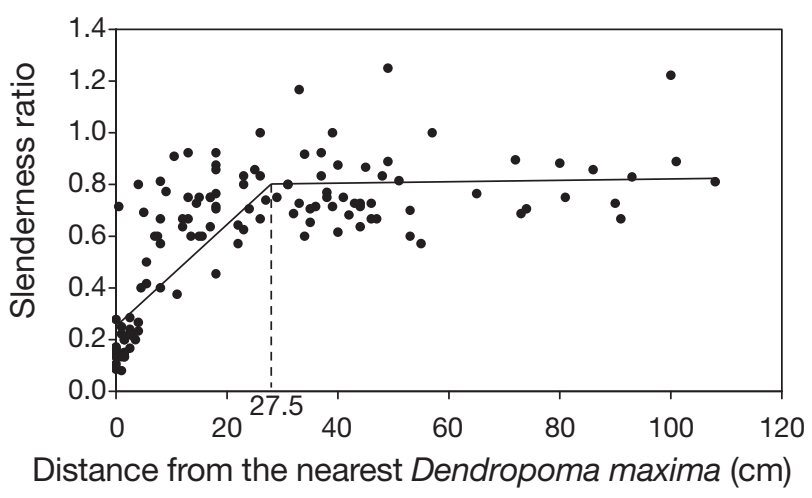

Fig. 2. Stylophora pistillata. Slenderness ratio (SR, height: diameter ratio) of corals on the reef flat as a function of distance from the nearest vermetid gastropod, Dendropoma maxima ( $\mathrm{n}=122)$. The breakpoint was estimated from a piecewise linear regression analysis as $27.5 \mathrm{~cm}$ (broken vertical line; $R^{2}=0.71$ ), indicating the radius of influence of the gastropod on the SR of corals 
no trend subsequently. The KS test showed that corals located within the range of influence of the gastropods ( $n=72$ ), as defined by the PLR analysis, were found to have a significantly smaller SR ( $p<0.001$; Fig. $3 C)$ than those located outside $(\mathrm{n}=50)$. In addition, they were found to be significantly smaller in both vertical dimension (i.e. height, $\mathrm{p}<0.001$; Fig. 3A) and diameter $(\mathrm{p}=0.001 ;$ Fig. 3B).

\section{Abundance of Dendropoma maxima across the reef flat}

The results of this study revealed the same pattern of abundance of the gastropod across the 3 zones on the reef flat as reported by Ribak et al. (2005): highest in the seaward edge, intermediate in the mid-reef and lowest in the shoreward edge (Fig. 4). However, our findings also show that along these 3 zones, over the last $9 \mathrm{yr}$, the density of the gastropod has increased by
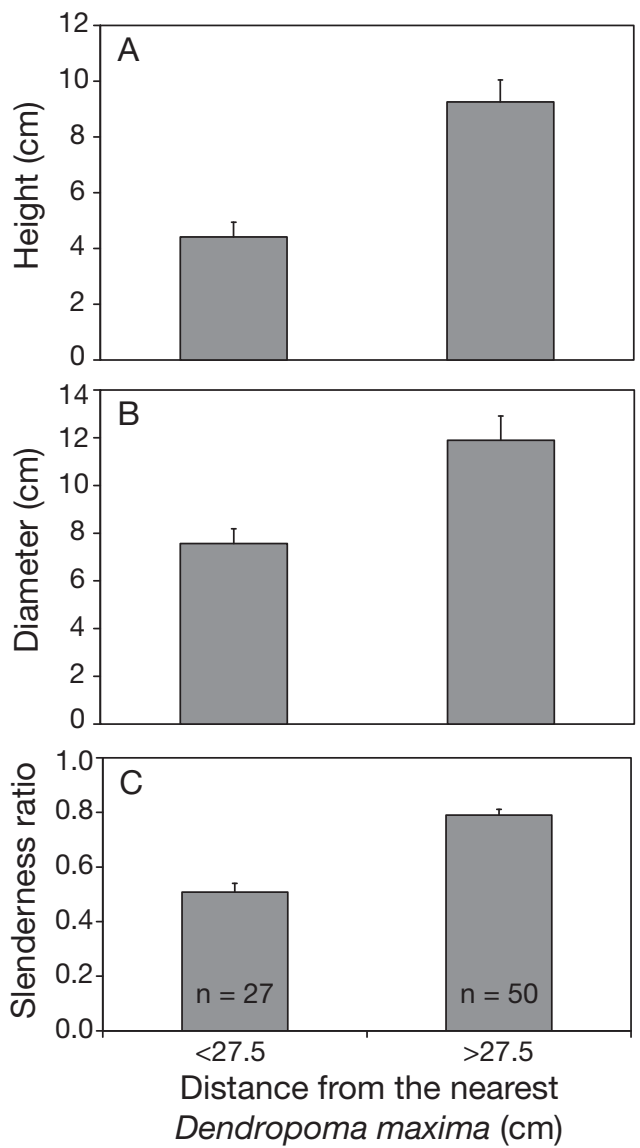

Fig. 3. Stylophora pistillata. (A) Mean height, (B) diameter and $(\mathrm{C})$ slenderness ratio (SR) within $(\mathrm{n}=72)$ and outside $(n=50)$ the radius of influence of the gastropod $(=27.5 \mathrm{~cm}$ as indicated from a piecewise linear regression analysis). Error bars are $\mathrm{SE}$

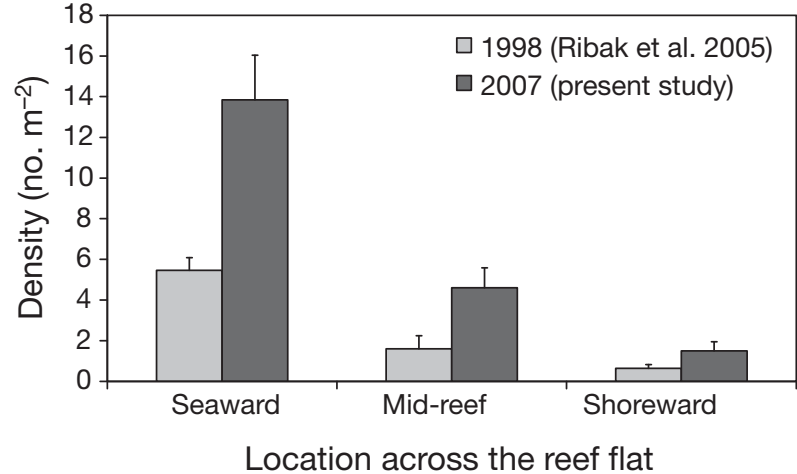

Fig. 4. Dendropoma maxima. Average population density measured along the reef flat at 3 parallel transects across the reef flat (seaward, mid-reef and shoreward), during 1998 (white bars, Ribak et al. 2005) and 2007 (black bars, present study). $\mathrm{n}=20$ for each transect in both studies. Error bars are SE

a factor of approx. 2.5 (2-way ANOVA, p < 0.01). Along the seaward edge, where the gastropod is most abundant, the density has increased from $5.5 \pm 0.6$ to $13.9 \pm$ 2.2 gastropods $\mathrm{m}^{-2}$ (mean $\pm \mathrm{SE}$ ) with a maximum value of 36 gastropods per $1 \mathrm{~m}^{2}$ quadrat. Over a scale of $1 \mathrm{~m}^{2}$, the gastropods were found to be very clumped along the 3 zones on the reef flat $(p<0.001)$, forming some patchy areas completely covered by merged mucus nets (e.g. Fig 1F).

\section{DISCUSSION}

\section{Deformation of corals}

We have demonstrated that the proximity of Dendropoma maxima plays a significant role not only in deforming coral morphology (Figs. 2 \& 3C), but also in limiting the vertical and horizontal dimensions of the coral (Fig. 3A,B). It is thus reasonable to assume that since corals and gastropods compete for mass transfer, the ability of the gastropod to limit the coral from extending in any dimension (whether deliberately or not) provides the gastropod with a competitive advantage over the corals. However, it is more essential for the gastropods to limit the vertical dimension of the corals. Since the former use horizontal local currents to spread their mucus net, corals located in the vicinity of the gastropods, and protruding higher than them, may limit the area over which the gastropods are able to secrete their mucus net. Protruding corals with a high SR may become barriers for the gastropod's mucus net if they are located downcurrent from the gastropod, or they may block the current that the gastropods use to spread their net if they are located upcurrent from the gastropod. In contrast, flattened corals enable the gas- 
tropod's mucus net to spread over the coral head and cannot block the horizontal component of the local currents, so the mucus net may be secreted over a larger area. In addition, it is possible that flattened branching corals may minimize the chances of the mucus net of becoming tangled with the coral branches and lost when the gastropod attempts to retrieve it. Indeed, as can be seen from Fig. 3A, $B$, the reduction in size of affected corals is more pronounced in their height (approx. 52\% lower, $\mathrm{p}<0.001$ ) than in their diameter (approx. 35\% smaller, $\mathrm{p}=0.001$ ), leading to a SR approx. $35 \%$ smaller $(p<0.001)$ for corals located within the range of $D$. maxima influence.

\section{Increased abundance of Dendropoma maxima}

The reason for the significant increase in gastropod density is currently unknown. However, filter feeders that occupy the reef surface are known to increase in density in response to enrichment with nutrients and particulate organic matter $\left(\mathrm{POM}_{i}\right.$ Birkeland 1977, Smith et al. 1981, Costa et al. 2000). For example, eutrophication in Kaneohe Bay, Hawaii, was considered as the primary cause of a community level phase shift from a coral-dominated community to one primarily dominated by macroalgal and suspension- and filter-feeding organisms (Smith et al. 1981, Hunter \& Evans 1995). Similarly, the increase in abundance of Dendropoma maxima over the past decade may be linked to the major environmental shift caused by eutrophication in the northern Gulf of Aqaba, altering the character of this basin from oligotrophic towards eutrophic (Lazar et al. in press). In general, deterioration of coral communities in this region during the last decade was suggested to be linked to this environmental change (Loya 2007). Specifically, other negative effects of suspension feeders on coral growth form shown recently in this region suggested that spionid polychaete worm infestations of massive corals in Eilat are related to nutrient enrichment (Wielgus et al. 2006). Similarly, Shenkar \& Loya (in press) suggested that the recent increase in anthropogenic activity (nutrient enrichment) in the Eilat reefs has created favorable conditions for filter-feeding organisms, such as ascidians, generating an advantage over reefbuilding corals in competition for space.

Although in this work we describe structural deformation of corals associated with sessile gastropods, the physiological effects of the gastropod's mucus net on corals and the mechanism behind this phenomenon were beyond the scope of this study. However, we suggest the following hypotheses to be tested in future work: (1) mucus nets reduce the water flow around the corals and prevent them from feeding on plankton (offered by Colgan in Smalley 1984), (2) mucus nets contain chemicals that inhibit coral growth, (3) Dendropoma maxima consumes the coral's metabolites, such as coral's mucus (suggested by Fenner 2006), and (4) this association with gastropods negatively affects coral reproduction.

Our results suggest that the vermetid gastropod Dendropoma maxima may negatively affect branching corals. In addition, we found that during the last decade the population of $D$. maxima on the reef flat in Eilat has significantly increased in abundance. The competitive advantage of gastropods over corals, coupled with the fact that their abundance has dramatically increased, demands further monitoring to examine the possibility of a potential change of this reef flat coral community to a simpler, filter-feeder-based community.

Acknowledgements. This work was supported in part by the Israel Science Foundation (ISF) and the World Bank and the Global Environmental Facility (GEF) through the Coral Reef Targeted Research and Capacity Building for Management program, Coral Bleaching and Local Environmental Responses working group. We thank Y. Shaked, J. Belmaker, R. van Woesik, E. Kramarsky-Winter, E. Meroz-Fine and G. Ribak for reviewing the manuscript, N. Paz for her editorial assistance and Y. Artzy-Randrup, A. Genin, O. Khaner, G. Yahel and M. Kiflawi for helpful discussions.

\section{LITERATURE CITED}

Birkeland C (1977) The importance of biomass accumulation in early successional stages of benthic communities to the survival of coral recruits. In: Taylor DL (ed) Proc 3rd Int Coral Reef Symp, Miami, FL, p 15-21

Costa OS Jr, Leao ZM, Nimmo M, Attrill MJ (2000) Nutrification impacts on coral reefs from northern Bahia, Brazil. Hydrobiologia 440:307-415

Fenner D (2006) Is a mollusc that sculptures coral a parasite? Proc 82nd Aust Coral Reef Soc Conf, Aug 2006, Mission Beach, N Queensland

Hughes RN, Lewis AH (1974) On the spatial distribution, feeding and reproduction of the vermetid gastropod Dendropoma maximum. J Zool 172:531-547

Hunter CL, Evans CW (1995) Coral reefs in Kaneohe Bay, Hawaii: two centuries of western influence and two decades of data. Bull Mar Sci 57:501-515

Kappner I, Al-Moghrabi SM, Richter C (2000) Mucus-net feeding by the vermetid gastropod Dendropoma maxima in coral reefs. Mar Ecol Prog Ser 204:309-313

Keen AM (1961) A proposed reclassification of the gastropod family Vermetidea. Bull Br Mus (Nat Hist) Zool 7:183-213

Lazar B, Erez J, Silverman J, Rivlin T and others (in press) Recent environmental changes in the chemical-biological oceanography of the Gulf of Aqaba (Eilat). In: Por FD (ed) Aqaba-Eilat, the improbable gulf. Environment, biodiversity and preservation. Magnes Press, Jerusalem

Loya Y (2007) How to influence environmental decision makers? The case of Eilat (Red Sea) coral reefs. J Exp Mar Biol Ecol 344:35-53

McCook LJ (2001) Competition between corals and algal turfs along a gradient of terrestrial influence in the nearshore central Great Barrier Reef. Coral Reefs 19:419-425 
Morton JE (1950) Feeding mechanisms in the Vermetidae (order Mesogastropoda). Nature 165:923-924

Ribak G, Heller J, Genin A (2005) Mucus-net feeding on organic particles by the vermetid gastropod Dendropoma maximum in and below the surf zone. Mar Ecol Prog Ser 293:77-87

Shenkar N, Loya Y (in press) New data on the ascidian fauna of the Gulf of Eilat (Aqaba). In: Por FD (ed) Aqaba-Eilat, the improbable gulf. Environment, biodiversity and preservation. Magnes Press, Jerusalem

Smalley TL (1984) Possible effect of intraspecific competition on the population structure of a solitary vermetid mollusc. PSZN I: Mar Ecol 14:139-144

Smith SV, Kimmener WJ, Laws EA, Brock RE, Walsh TW (1981) Kaneohe Bay sewerage diversion experiment: perspectives on ecosystem response to nutritional perturba-

Editorial responsibility: Charles Birkeland,

Honolulu, Hawaii, USA tion. Pac Sci 35:279-395

Southwood TRE, Henderson PA (2000) Ecological methods, 3rd edn. Blackwell Science, Oxford

Toms JD, Lesperance ML (2003) Piecewise regression: a tool for identifying ecological thresholds. Ecology 84:2034-2041

Wielgus J, Glassom D, Chadwick NE (2006) Patterns of polychaete worm infestation of stony corals in the northern Red Sea and relationships to water chemistry. Bull Mar Sci 78:377-388

Zuschin M, Hohenegger J, Steininger FF (2001) Molluscan assemblages on coral reefs and associated hard substrata in the northern Red Sea. Coral Reefs 20:107-116

Zvuloni A, Artzy-Randrup Y, Stone L, van Woesik R, Loya Y (2008) Ecological size-frequency distributions: how to prevent and correct biases in spatial sampling. Limnol Oceanogr Methods 6:144-153

Submitted: January 4, 2008; Accepted: March 5, 2008 Proofs received from author(s): June 18, 2008 